\title{
Study to assess proper timing of laryngoscopy in post-thyroid surgery patients to detect recurrent laryngeal nerve injury
}

\author{
Tausif Ahmad', Abdur Rahman², Aftab Ahmed ${ }^{3}$, Mehtab Alam ${ }^{4}$, Shruti Chand ${ }^{5}$ \\ ${ }^{1}$ ENT Specialist, Department of ENT, Sadar Hospital Purnea, Bihar, ${ }^{2}$ Assistant Professor, ${ }^{5} \mathrm{~J}$ unior Resident, Department \\ of ENT, Rohilkhand Medical College and Hospital, Bareilly, Uttar Pradesh, ${ }^{3,4}$ Associate Professor, Department of ENT, \\ J.N. Medical College and Hospital, Aligarh Muslim University, Aligarh, Uttar Pradesh, India
}

Background: Thyroid surgeries are commonly done nowadays for benign and malignant conditions. Recurrent laryngeal nerve palsy (RLNP) is an important and potentially catastrophic complication of thyroid surgery. The purpose of the study was to determine the impact of rigid endoscopy (Hopkins rod-lens telescope) performed at different time intervals on the diagnosis of RLNP in post-thyroid surgery patients. Aims and Objectives: To assess Proper Timing of Laryngoscopy in Post-thyroid Surgery patients to Detect RLN Injury. Materials and Methods: Rigid endoscopy was performed postoperatively at day $0\left(T_{0}\right)$, at $2^{\text {nd }}$ day post-op $\left(T_{1}\right)$, and day $14\left(T_{2}\right)$. For patients with RLNP, repeated examinations were performed at 2 months $\left(T_{3}\right), 6$ months $\left(T_{4}\right)$, and 12 months $\left(T_{5}\right)$. Results: The study included 50 patients of thyroid swelling with different diagnoses. Overall, 35 patients appeared for postoperative laryngoscopic examination of the vocal folds at our center, providing 61 nerves at risk. RLNP rate was $8.1 \%$ at $\mathrm{T}_{0}, 11.5 \%$ at $\mathrm{T}_{1}, 9.8 \%$ at $\mathrm{T}_{2}, 8.1 \%$ at $\mathrm{T}_{3^{\prime}}, 4.9 \%$ at $\mathrm{T}_{4^{\prime}}$ and $3.3 \%$ at $T_{5} . T_{1}$ was significantly superior to all other time intervals in terms of diagnosis of RLNP but statistically not significant. Conclusion: Rigid endoscopy is essential for the detection of vocal cord paralysis after thyroidectomy. We report different time evaluation criteria of vocal cord morbidity with great and significant variability of results. Second day post-op inspection of the larynx $\left(T_{1}\right)$ is suggested.

Key words: Laryngoscopy; Recurrent laryngeal nerve palsy; Thyroidectomy; Timing

\section{Access this article online}

Website:

http://nepjol.info/index.php/AJMS DOI: 10.3126/ajms.v12i12.39105

E-ISSN: 2091-0576

P-ISSN: 2467-9100

Copyright (c) 2021 Asian Journal of Medical Sciences

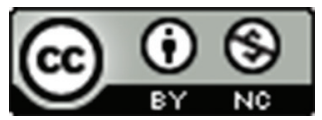

This work is licensed under a Creative Commons Attribution-NonCommercial 4.0 International License.

\section{INTRODUCTION}

The motor and sensory nerves of the larynx are derived from the vagus by way of its superior and recurrent laryngeal nerves (RLNs). ${ }^{1}$ The most frequent and unpleasant complication of thyroid surgery is a RLN injury due to intraoperative damage. It may occur during surgery because of direct mechanical trauma, either with or without disruption. Injury to the RLN post thyroid surgery associated with hoarseness, impaired voice, dysphonia, dysphagia, aspiration, dyspnea, and in many cases to a lifethreatening glottal obstruction. The reported incidence of temporary recurrent laryngeal nerve palsy (RLNP) ranges from $1.3 \%$ to $20 \%$, while the incidence of permanent RLNP varies from $0 \%$ to $9 \%$. These percentages are dependent on the type of surgery and thyroid gland disease..$^{2-5}$ RLN injury results in paralysis of all the intrinsic muscles of the larynx except the cricothyroid muscle which is supplied by the superior laryngeal nerve (SLN). There is an inability to abduct and adduct the vocal folds. ${ }^{6}$ RLN paralysis rate is higher in cancer, Graves disease, reoperation, sub sternalgoiter, in less experienced surgical centers, and in patients in whom the inferior laryngeal nerve could not be identified and or monitored during operation. ${ }^{7-10}$ The most frequent published mechanism of RLN injury is overstretching of the nerve at the region of Berry's ligament clamping or transecting of the nerve. The true overall injury rate of RLN is not yet delineated for several actual reasons: 
- No routine audit by centers performing thyroid surgery - not all patients infact undergo a systematic laryngeal examination in the postoperative period. ${ }^{11,12}$

- Lack of reliability of clinical symptoms in vocal cord paralysis.

- There is considerable variation in the reported frequency of RLNP rates after thyroid surgery due to the different methods of diagnosing RLNP, i.e. indirect laryngoscopy versus rigid endoscopy versus fiber-optic nasolaryngoscopy (FNL) versus video stroboscopy, each of which have significant different sensitivities and specificities. ${ }^{13}$

Rigid endoscopy offers improved visualization of the larynx through better illumination, higher magnification, and wider and deeper fields of vision.

The angled endoscopes allow better perspectives of the ventricle, free edge, and under the surface of the vocal cord. ${ }^{14}$ Assessment of vocal cord functions (VCFs) with a laryngoscope is of great importance in the preoperative and postoperative evaluation of patients undergoing thyroidectomy. ${ }^{15}$ Pre-operatively, VCF detects an existing RLNP from local invasion of the nerve by extra-thyroidal cancer extension or regional lymph node metastases. ${ }^{16,17,18}$ Postoperative assessment of VCF documents a well preserved VCF, or an iatrogenic RLN injury, and yet the benefits of speech, rehabilitation, steroid, and surgical treatment. There is currently a lack of consensus to support the proper timing for the postoperative laryngoscopy that is reliable to diagnose RLNP.

\section{Aims and objectives}

To assess Proper Timing of Laryngoscopy in Post-thyroid Surgery patients to Detect RLN Injury.

\section{MATERIALS AND METHODS}

This prospective study "Study to assess Proper Timing of Laryngoscopy in Post-thyroid Surgery patients to Detect RLN Injury" was conducted from 30 Nov 2011 to 30 Nov 2013 in 50 patients undergoing laryngoscopy in post thyroid surgery at different time intervals. The written and informed consent was obtained from each patient in advance for consecutive laryngoscopy. Pre- and post-operative follow-up include for all patients to check vocal cord mobility by laryngoscopy. Every patient in the study was evaluated on the basis of brief history, general and local examinations including indirect laryngoscopy and 900, 700 rigid endoscopy. Indirect mirror laryngoscopic findings were confirmed by rigid endoscopy (Hopkins rod-lens telescope- Figure 1)

\section{Inclusion criteria}

1. All patient of thyroid swelling.

2. All cases of different thyroid surgeries.

3. Patients who have given written informed consent for laryngoscopy, pre and post thyroid surgery.

4. Patients who have given written consent for follow up.

\section{Exclusion criteria}

1. Established preoperative injury to the laryngeal nerves.

2. Intraoperative finding of tumour involvement of RLN.

3. Patients who were lost during the follow-up study.

$70^{\circ}$ Or $90^{\circ}$ Hopkins rod-lens telescope/endoscope A rigid telescope with an angled lens of $70^{\circ}$ or $90^{\circ}$ can be passed through the mouth to the oropharynx to view the larynx. Twenty centimeters are often a comfortable telescope length for the endoscopist. The laryngeal examination with a $70^{\circ}$ rigid endoscope is conducted with the patient bending slightly forward from the hips while maintaining a straight back. The neck and chin are extended, and the tongue is protruded. The examiner wraps the tongue in gauze and holds it gently during the examination. The endoscope is advanced just under the uvula or between the uvula and faucial pillars until the epiglottis is visualized. Turning the endoscope tip to face the cheek during insertion, to prevent tongue residue from coating the lens, might keep the lens cleaner. Having the patient vocalize a sustained "hey" lowers the tongue base, facilitating placement. The patient is then instructed to sustain "ee," which moves the epiglottis anteriorly for a better view of the vocal folds. The examiner might need to flex the wrist to tilt the endoscope tip inferiorly. The angle can be varied for differing levels of magnification and differing fields of view. The patient is then guided through the examination tasks listed in the following "Assessment" section. Examination with the $90^{\circ}$ endoscope is similar, but the patient does not need to bend forward or extend the neck. Another difference is the angle; the tip of the $90^{\circ}$ scope is positioned with minimal tilt so that the light is parallel to the surface of the vocal folds. This type of endoscope is often preferable for viewing the larynx when a wider viewing angle is desired. A longer lens or a zoom lens might be necessary for adequate visualization of vocal fold details. Children as young as 6 or 8 years of age may be able to cooperate for this examination.

Laryngoscopy was performed at $24-48 \mathrm{~h}$ before operation $\left(T_{x}\right)$. Postoperatively patients were evaluated for RLN injury by laryngoscopy on the same day $\left(\mathrm{T}_{0}\right)$, on day $2\left(\mathrm{~T}_{1}\right)$ and on day $14\left(\mathrm{~T}_{2}\right)$.

RLNP is defined as newly discovered reduction in the movement of vocal folds after surgery compared with the 
preoperative status. For patients with postoperative cord palsy, repeated examinations were performed periodically at 2 months $\left(T_{3}\right), 6$ months $\left(T_{4}\right)$, and 12 months $\left(T_{5}\right)$. When laryngoscopy was found normal at $\mathrm{T}_{0}, \mathrm{~T}_{1}$ and $\mathrm{T}_{2}$ examination, the patients were not taken for further laryngoscopy.

\section{Ethics}

The procedures followed were in accordance with the ethical standards of the responsible committee on human experimentation (institutional or regional) and with the Helsinki Declaration of 1975, as revised in 1983.

\section{Statistical analysis}

Findings were noted and tabulated. Measurement of the RLNP rate was based on the number of nerves at risk (NAR). All data were analyzed statistically using statistical package for the social sciences 20 and Chi-square test for differences in postoperative RLNP rate and recovery days. Test was significant when $\mathrm{P}<0.05$. Then conclusions were drawn after analysis.

\section{RESULTS}

The present study was carried over a period of 2 years in the Department of Otorhinolaryngology, J. N. Medical College and Hospital A. M. U. Aligarh. The study included 50 patients of thyroid swelling with different diagnosis. All 50 patients scheduled for thyroidectomy underwent preoperative evaluation of the vocal folds. At pre-operative laryngeal examination, we found two alterations of vocal folds movement in 50 patients $(4 \%)$. Based on the exclusion criteria, these two patients ruled out the analysis.

Complete follow-up was available for $96 \%$ of patients (48/50). Five patients were unwilling to accept further laryngeal reexamination, and they were asymptomatic. Moreover, eight other patients were loss during the follow-up study.

Overall, 35 patients appear for post-operative laryngoscopic examination of the vocal folds at our center, providing 61 NAR for examination. Table 1 summarizes the distribution of epidemiological characteristics of patients, thyroid pathology, and procedures.

The RLN was virtually identified in all cases. No bilateral vocal cord paralysis occurred. Overall permanent RLNP occurred in $3.2 \%(n=2)$, while the temporary RLN injury in $8.1 \%(n=5)$. The rate of RLN morbidity shows a considerable variation due to the different time intervals of laryngoscopy. The rate of RLNP was $8.1 \%$ at $\mathrm{T}_{0} 5$ out of $61 \mathrm{NAR}), 11.5 \%$ at $\mathrm{T}_{1} 7$ out of $\left.61 \mathrm{NAR}\right), 9.8 \%$ at $\mathrm{T}_{2}$ $(\mathrm{n}=6), 8.1 \%$ at $\mathrm{T}_{3}(\mathrm{n}=5), 4.9 \%$ at $\mathrm{T}_{4}(\mathrm{n}=3)$, and $3.3 \%$ at $\mathrm{T}_{5}$ $(\mathrm{n}=2)$, according to different time intervals of laryngoscopy in the postoperative period.

\begin{tabular}{|c|c|}
\hline \multicolumn{2}{|l|}{ Parameters study group } \\
\hline Age (years) & $35.89(18-58)$ \\
\hline Women $(\mathrm{N})$ & 25 \\
\hline $\operatorname{Men}(\mathrm{N})$ & 10 \\
\hline Lobectomy & $9(25.7 \%)$ \\
\hline Total thyroidectomy & $2(5.7 \%)$ \\
\hline Subtotal thyroidectomy & $17(48.6 \%)$ \\
\hline Revised near total thyroidectomy & $2(5.7 \%)$ \\
\hline Near-total thyroidectomy & $5(14.3 \%)$ \\
\hline Nerves at risk & 61 \\
\hline \multicolumn{2}{|l|}{ Preoperative diagnosis } \\
\hline Multinodular goiter & $9(25.7 \%)$ \\
\hline Papillary carcinoma & $2(5.7 \%)$ \\
\hline Goitre with left complex cyst 1 & $(2.9 \%)$ \\
\hline Left thyroid cyst 2 & $(5.7 \%)$ \\
\hline Recurrent multinodular goiter & $2(5.7 \%)$ \\
\hline Simple colloid goiter & $13(37.1 \%)$ \\
\hline Left solitary nodular goiter & $2(5.7 \%)$ \\
\hline Right solitary nodular goiter & $3(8.6 \%)$ \\
\hline Right thyroid cyst & $1(2.9 \%)$ \\
\hline Hyperthyroidism & $2(5.7 \%)$ \\
\hline
\end{tabular}

In our study, the rate of detection of RLNP at $\mathrm{T}_{1}$ (day 2) was superior as compared to other time intervals of laryngoscopy, but it is statistically insignificant $(\mathrm{P}>0.05)$.

\section{DISCUSSION}

Thyroid surgeries are commonly done nowadays for benign and malignant conditions. There is a need to know the complications of surgeries for the post-operative management of the patients to prevent morbidity and mortality. RLNP is an important and potentially catastrophic complication of thyroid surgery. Voice dysfunction after thyroidectomy is not rare and is generally reported in terms of RLN or SLN injuries. However, voice dysfunction can occur without laryngeal nerves injuries. Prompt recognition of causes of dysphonia is essential so that relevant therapeutic decision allows early management. During recent years, intraoperative nerve monitoring has been introduced to decrease the frequency of nerve injuries during thyroid surgery. It has been argued that in expert hands, the risk is very low..$^{17,18}$

Pre and post-operative laryngoscopy is required to detect RLN injury accurately. Pre-operative vocal cord evaluation will ensure adequate diagnosis and documentation, aid surgical planning and consent, and reduce any medicolegal implications. In our study 50 patients scheduled for thyroidectomy underwent preoperative evaluation of the vocal folds, we found alterations of vocal folds movement in 2 patients $(4 \%)$.

The result of our study was also in accordance with the study conducted by Sayyahmelli et al., ${ }^{18}$ who studied 100 patients 
scheduled for thyroidectomy, there were 89 cases who had benign disease of thyroid and 11 cases of malignancy. Modification of voice and impaired vocal fold motion were seen in 11 and seven patients before operation, respectively, and emphasized the need of preoperative examination of the larynx of patients undergoing surgery for thyroid gland. Likewise, the absence of abnormality in voice would not accurately rule out the probability of vocal fold or laryngeal nerve lesions. This is the second study done to evaluate the impact of time interval of the post-operative laryngoscopy for the diagnosis of RLN injury after thyroid surgery. The potential, useful, and proper timing of laryngeal inspection for the diagnosis of RLNP is not well documented in literature. This study identifies that the wide variation of rates of RLNP is dependent even upon the day of vocal cord assessment in the early post-operative period. The post thyroidectomy laryngoscopic finding in our study (Table 2) is that rate of detection of RLNP is superior at T1 (2nd post-operative day) as compared to other days, i.e., T0 (at the day of thyroidectomy), T2 (2 weeks), T3 (2 months), T4 (6 months), and T5 (12 months). The rate of detection of RLNP noticeably reduced as the time interval of laryngoscopy increased. The reason for the superior sensitivity of RLNP rate detection at $\mathrm{T}_{1}$ as compared to other days (i.e., $\mathrm{T}_{2}, \mathrm{~T}_{3}, \mathrm{~T}_{4}$ and $\mathrm{T}_{5}$ ) may be associated with the extent of RLN injury, varying in its severity from neurapraxia to axonotmesis and neurotmesis. Studies showed that RLNP process subdues from the very $1^{\text {st }}$ days post-operative. $^{18}$

Wagner and Seiler, ${ }^{19}$ Chiang et al., ${ }^{20}$ and Snyder et al., ${ }^{21}$ noted that their cases of temporary paralysis resolved in starting early from the $3^{\text {rd }}$ post-operative day.

Karlan et al., ${ }^{22}$ described cases of transient paralysis with recovery ranging from the $1^{\text {st }}$ week postoperative. In fact, partial injuries (neurapraxia) are much more common than complete transaction (neurotmesis).

Chiang et al., ${ }^{23}$ reported a recovery from temporary RLNP from 3 days to 4 months (mean, 30.7 days). While after neurotmesis has occurred, no such recovery would be seen. Therefore, most studies suggest that a follow-up period of 12 months minimum is needed to assess voice function after if dysphonia is detected after thyroid surgery.

The reason of the superior sensitivity of $T_{1}$ compared to $\mathrm{T}_{0}$ may be associated to patient's poor compliance, self-adherence, and the degree to which he/she correctly follows medical advice during the laryngoscopy early after extubation $\left(\mathrm{T}_{0}\right)$ and early complications of intubation, i.e. vocal cord congestion and edema hinder correct assessment of VCFs. Factors that may decrease patient's compliance in $\mathrm{T}_{0}$ include patient feeling ill, limitations of patients activities due to the anesthesia state, acute illness, local pain, poor analgesia support, purpose of laryngoscopy not clear, instructions for laryngoscopy not clear, physical difficulty in complying laryngoscopy, and unattractive/unpleasant examination. This result of our study was also in accordance with the study conducted by Dionigi et al., ${ }^{24}$ (2010) performed FNL of 434 post thyroid surgery patients at different time intervals. They recorded rate of RLNP $6.4 \%$ at day $0\left(\mathrm{~T}_{1}\right), 6.7 \%$ at day $2\left(\mathrm{~T}_{2}\right), 4.8 \%$ at 2 week $\left(\mathrm{T}_{3}\right), 2.5 \%$ at 2 months $\left(\mathrm{T}_{4}\right), 0.8 \%$ at 6 months $\left(\mathrm{T}_{5}\right)$ and $0.7 \%$ at 12 months $\left(\mathrm{T}_{6}\right)$. They suggested day $2\left(\mathrm{~T}_{2}\right)$ post-operative FNL is superior to detect RLN injury.

Most European, as well as American thyroid association's guidelines, recommend laryngoscopy only for voice dysfunction persisting beyond 2 weeks after thyroidectomy. ${ }^{25,26}$

Studies that evaluated the rates of RLN injury after a thyroid surgery reported considerable variation in the reported frequency of vocal cord palsy rates due to the different reasons to perform laryngoscopy postoperatively, i.e., to all patients or only patients with impaired voice register. Moreover, due to different periods of time (as at extubation, hospital discharge, and weeks after surgery) of which we now demonstrated have significant different sensitivities and specificities. ${ }^{15}$ All patients should undergo pre- and post-operative laryngeal examination if we need to appreciate the true rate at which RLN injury occurs.

It is impossible to diagnose RLNP without performing the laryngeal examination, and also to use the benefits of speech, steroid therapy, surgery, and rehabilitation. ${ }^{27-30}$ Uniform and standard criteria for evaluating the VCF after surgery are certainly needed to plan an effective and early treatment and also to be able to compare the results among different centers.

In our study, we noted permanent RLNP in 3.3\% of thyroid surgeries, temporary RLN injury in $8.2 \%$ while none had bilateral RLNP. We have noted that approximately 57\% of those RLNP recovered within 6 months, and $71 \%$ in 12 months. Thus, permanent RLN paralysis may be diagnosed on the basis of serial laryngeal examinations between the period of 6 and 12 months after a thyroid surgery. Therefore, through our study, we suggest followup period of 12 months minimum to assess the voice function after thyroidectomy surgery, if any dysphonia is detected (Figure 2). This is similar with other studies where the period of follow-up for RLNP after a thyroid surgery was 1 year. ${ }^{2}$ 


\begin{tabular}{|c|c|c|c|}
\hline $\begin{array}{l}\text { Timing of } \\
\text { Laryngoscopy }\end{array}$ & $P$ value & $\begin{array}{c}\text { Chi-square } \\
\text { value }\left(\chi^{2}\right)\end{array}$ & $\begin{array}{c}\text { Degree of } \\
\text { freedom }\end{array}$ \\
\hline $\mathrm{T}_{0}($ day 0$)$ & 0.543 & 0.370 & 1 \\
\hline $\mathrm{T}_{2}$ (day 14) & 0.769 & 0.086 & 1 \\
\hline $\mathrm{T}_{3}(2$ months $)$ & 0.543 & 0.370 & 1 \\
\hline $\mathrm{T}_{4}(6$ months $)$ & 0.322 & 0.980 & 1 \\
\hline $\mathrm{T}_{5}$ (12 months) & 0.166 & 1.919 & 1 \\
\hline
\end{tabular}

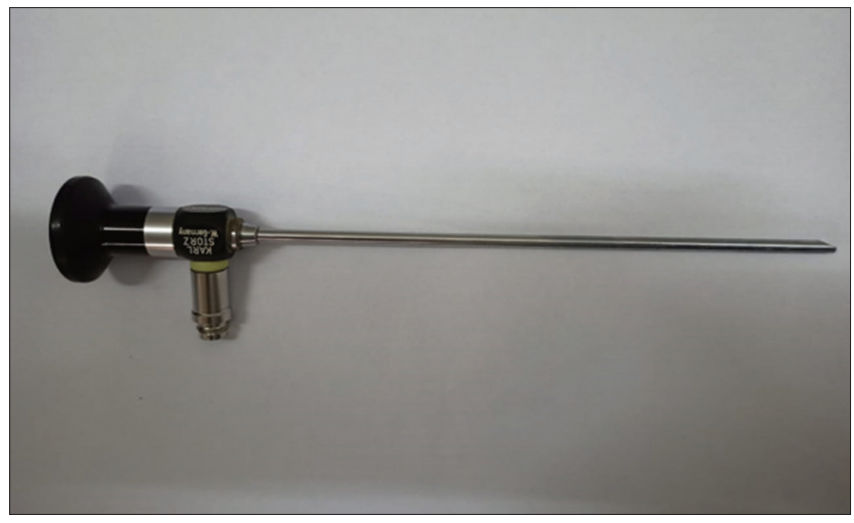

Figure 1: $70^{\circ}$ Hopkins rod-lens telescope/endoscope

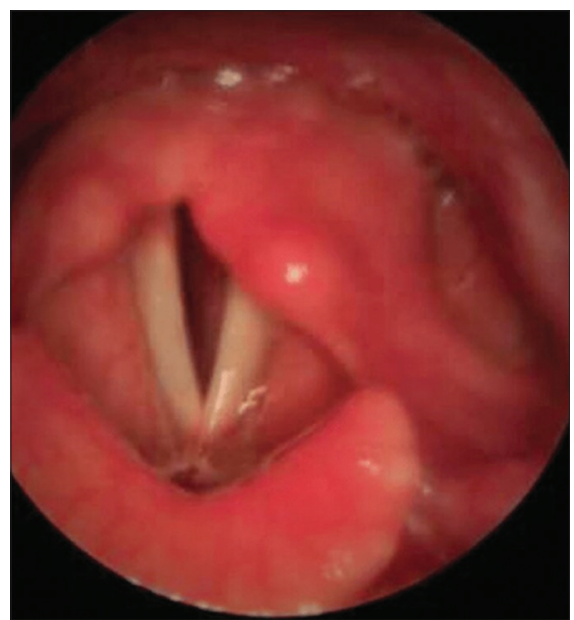

Figure 2: $90^{\circ}$ Endoscopic view of left vocal cord palsy/left recurrent laryngeal nerve injury (Post-operative)

Jeannon et al., shows in their study that average rate of temporary RLNP after thyroid operations is $9.8 \%$, and of permanent RLNP is $2.3 \%$. According to the method of examining the larynx, the RLNP rate varied and it ranged from $26 \%$ to $2.3 \%$. Most of the studies which are reviewed recommend a period of follow-up till 1 year to assess and evaluate RLNP.

\section{Limitations of the study}

The present study has some limitations. The sample size was small.

\section{CONCLUSION}

Although the incidence of laryngeal nerve palsy after thyroidectomy is low, the condition has to be promptly recognized and investigated by the surgeon. The variable symptoms that occur are cough, dysphonia, dysphagia, and dyspnea. Their intensity and association are variable. We propose different interval time evaluation criteria of vocal cord mobility post-thyroid surgery. The rate of RLNP is influenced by the "timing" of the postoperative laryngoscopy. We conclude that proper timing of laryngeal inspection for the diagnosis of RLNP is on $2^{\text {nd }}$ postoperative day.

\section{ACKNOWLEDGMENT}

We thank all the authors of this article who made this research possible

\section{REFERENCES}

1. Brok HA, Copper MP, Stroeve RJ, de Visser BW, Venker-van Haagen AJ and Schouwenburg PF. Evidence for recurrent laryngeal nerve contribution in motor innervation of the human cricopharyngeal muscle. Laryngoscope. 1999;109(5):705-708. http://doi.org/10.1097/00005537-199905000-00005

2. Altorjay A, Tihanyi Z, Luka F, Juhasz A, Bencsik Z, Rull M, et al. Place and value of the Recurrent Laryngeal Nerve (RLN) palpatory method in preventing RLN palsy during thyroid surgery. Head Neck. 2009;31(4):538-647.

http://doi.org/10.1002/hed.20996

3. Efremidou EI, Papageorgiou MS, Liratzopoulos $\mathrm{N}$ and Manolas KJ. The efficacy and safety of total thyroidectomy in the management of benign thyroid disease: A review of 932 cases. Can J Surg. 2009;52(1):39-44.

4. Jeannon JP, Orabi AA, Bruch GA, Abdalsalam HA and Simo R. Diagnosis of recurrent laryngeal nerve palsy after thyroidectomy: A systematic review. Int J Clin Pract. 2009;63(4):624-629.

http://doi.org/10.1111/j.1742-1241.2008.01875.x

5. Sywak MS, Yeh MW, Sidhu SB, Barraclough BH and Delbridge LW. New surgical consultants: Is there a learning curve? ANZ J Surg. 2006;76(12):1081-4. http://doi.org/10.1111/j.1445-2197.2006.03950.x

6. Perry A. Speech therapy in ENT practice: Scope, science and evidence for intervention. In: Gleeson M, editor. Scott-Brown's Otolaryngology, Head and Neck Surgery. 7th ed. Great Britain: Hodder Arnold; 2008. p. 2216-33.

7. Lahey FH and Hoover WB. Injuries to the recurrent laryngeal nerve in thyroid operations: Their management and avoidance. Ann Surg. 1938;108(4):545-562.

http://doi.org/10.1097/00000658-193810000-00006

8. Hermann M, Alk G, Roka R, Glaser K and Freissmuth $M$. Laryngeal recurrent nerve injury in surgery for benign thyroid diseases: Effect of nerve dissection and impact of individual surgeon in more than 27,000 nerves at risk. Ann Surg. 2002;235(2):261-268.

http://doi.org/10.1097/00000658-200202000-00015

9. Thomusch O, Machens A and Sekulla C. Multivariate analysis 
of risk factors for postoperative complications in benign goiter surgery: Prospective multicenter study in Germany. World J Surg. 2000;24(11):1335-1341. http://doi.org/10.1007/s002680010221

10. Barczynski M, KonturekA and Cichon S. Randomized clinical trial of visualization versus neuromonitoring of recurrent laryngeal nerves during thyroidectomy. Br J Surg. 2009;96(3):240-246. http://doi.org/10.1002/bjs.6417

11. Bergenfelz $A$, Jansson $S$, Kristoffersson $A$, Mårtensson $H$, Reihnér $\mathrm{E}$, Wallin $\mathrm{G}$, et al. Complications to thyroid surgery: Results as reported in a database from a multicenter audit comprising 3,660 patients. Langenbeck's Arch Surg. 2008;393(5):667-673.

http://doi.org/10.1007/s00423-008-0366-7

12. Randolph GW and Kamani D. The importance of preoperative laryngoscopy in patients undergoing thyroidectomy: Voice, vocal cord function, and the preoperative detection of invasive thyroid malignancy. Surgery. 2006;139(3):357-362.

http://doi.org/10.1016/j.surg.2005.08.009

13. Jeannon JP, Macnamara M. Assessment and examination of the upper respiratory tract. In: Gleeson M, editor. Scott-Brown's Otorhinolaryngology: Head and Neck Surgery. $7^{\text {th }}$ ed., Vol. 2. Great Britain: Hodder Arnold; 2008. p. 2145-52.

14. Farrag TY, Samlan RA, Lin FR and Tufano RP. The utility of evaluating true vocal fold motion before thyroid surgery. Laryngoscope. 2006;116(2):235-238.

http://doi.org/10.1097/01.mlg.0000191472.02720.1f

15. Randolph GW, editor. Surgical anatomy of the recurrent laryngeal nerve. In: Surgery of the Thyroid and Parathyroid Glands. Philadelphia, PA: Elsevier Science; 2003.

16. Echternach M, Maurer CA, Mencke T, Schilling M, Verse T and Richter B. Laryngeal complications after thyroidectomy: Is it always the surgeon? Arch Surg. 2009;144(2):149-153. http://doi.org/10.1001/archsurg.2008.530

17. Schlosser K, Zeuner M, Wagner M, Slater EP, Fernández ED, Rothmund $M$ and Maschuw K. Laryngoscopy in thyroid surgery: Essential standard or unnecessary routine? Surgery. 2007;142(6):858-864.

http://doi.org/10.1016/j.surg.2007.09.008

18. Sayyahmelli M, Alipanahi R, Ghorjanian A and Mousavipanah S. Value of laryngoscopy before and after thyroidectomy. Rawal Med J. 2009;34:89-91.

19. Wagner $\mathrm{HE}$ and Seiler $\mathrm{C}$. Recurrent laryngeal nerve palsy after thyroid gland surgery. Br J Surg. 1994;81(2):226-28. http://doi.org/10.1002/bjs.1800810222

20. Chiang FY, Lu IC and Kuo WR. The mechanism of recurrent laryngeal nerve injury during thyroid surgery the application of intraoperative neuromonitoring. Surgery. 2008;143(6):743-749. http://doi.org/10.1016/j.surg.2008.02.006

21. Snyder SK, Lairmore TC, Hendricks JC and Roberts JW. Elucidating mechanisms of recurrent laryngeal nerve injury during thyroidectomy and parathyroidectomy. J Am Coll Surg. 2008;206(1):123-130.

http://doi.org/10.1016/j.jamcollsurg.2007.07.017

22. Karlan MS, Catz B, Dunkelman D, Uyeda RY and Gleischman S. A safe technique for thyroidectomy with complete nerve dissection and parathyroid preservation. Head Neck Surg. 1984;6(6):1014-1019. http://doi.org/10.1002/hed.2890060606

23. Chiang FY, Wang LF, Huang YF, Lee KW and Kuo WR. Recurrent laryngeal nerve palsy after thyroidectomy with routine identification of the recurrent laryngeal nerve. Surgery. 2005;137(3):342-347. http://doi.org/10.1016/j.surg.2004.09.008

24. Dionigi G, Boni L, Rovera F, Rausai S, Castelnuovo P and Dionigi R. Postoperative laryngoscopy in thyroid surgery: Proper timing to detect recurrent laryngeal nerve injury. Langenbecks Arch Surg. 2010;395(4):327-331. http://doi.org/10.1007/s00423-009-0581-x

25. Watkinson JC and British Thyroid Association. The British thyroid association guidelines for the management of thyroid cancer in adults. Nucl Med Commun. 2004;25(9):897-900. http://doi.org/10.1097/00006231-200409000-00006

26. Cooper DS, Doherty GM, Haugen BR, Kloos RT, Lee SL, Mandel SJ, et al. Management guidelines for patients with thyroid nodules and differentiated thyroid cancer. Thyroid. 2006;16(2):109-142. http://doi.org/10.1089/thy.2006.16.109

27. Miller S. Voice therapy for vocal fold paralysis. Otolaryngol Clin North Am. 2004;37(1):105-119. http://doi.org/10.1016/S0030-6665(03)00163-4

28. Laccourreye O, Papon JF, Kania R, Crevier-Buchman L, Brasnu $D$ and Hans S. Intracordal injection of autologous fat in patients with unilateral laryngeal nerve paralysis: Long-term results from the patient's perspective. Laryngoscope. 2003;113(3):541-545. http://doi.org/10.1097/00005537-200303000-00027z

29. Seddon H. Nerve injuries. Med Bull (Ann Arbor). 1965;31:4-10.

30. Kelchner LN, Stemple JC, Gerdeman E, Le Borgne W and Adam S. Etiology, pathophysiology, treatment choices, and voice results for unilateral adductor vocal fold paralysis: A 3-year retrospective. J Voice. 1999;13(4):592-601. http://doi.org/10.1016/s0892-1997(99)80013-7

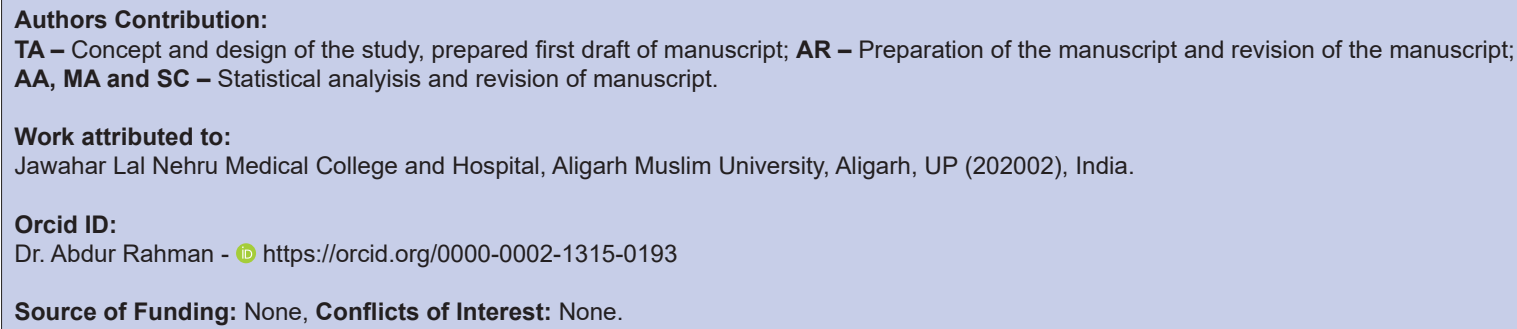

